\title{
Modulating epigenetic memory through vitamins and TET: implications for regenerative medicine and cancer treatment
}

\begin{abstract}
Vitamins $A$ and $C$ represent unrelated sets of small molecules that are essential to the human diet and have recently been shown to intensify erasure of epigenetic memory in naive embryonic stem cells. These effects are driven by complementary enhancement of the ten-eleven translocation (TET) demethylases - vitamin A stimulates TET expression, whereas vitamin C potentiates TET catalytic activity. Vitamin A and C cosupplementation synergistically enhances reprogramming of differentiated cells to the naive state, but overuse may exaggerate instability of imprinted genes. As such, optimizing their use in culture media will be important for regenerative medicine and mammalian transgenics. In addition, mechanistic perception of how these vitamins interact with the epigenome may be relevant for understanding cancer and improving patient treatment.
\end{abstract}

First draft submitted: 5 February 2017; Accepted for publication: 27 March 2017; Published online: 30 May 2017

Keywords: 5 -Hydroxymethylcytosine $\bullet$ DNA methylation $\bullet$ epigenetic erasure $\bullet$ epigenetic memory $\bullet$ naive pluripotency $\bullet$ regenerative medicine $\bullet$ reprogramming $\bullet$ retinoic acid

- retinol $\bullet$ TET $\bullet$ transgenics $\bullet$ vitamin A $\bullet$ vitamin C

Vitamins $\mathrm{A}$ and $\mathrm{C}$ represent distinct sets of dietary micronutrients (Figure $1 \mathrm{~A}$ ), and both are associated with a long recorded history. Nightblindness, an early symptom of vitamin A deficiency, and its cure through liver consumption, was known to Egyptians in the prehistoric period [1]. Equally, the debilitating effects of scurvy (vitamin $\mathrm{C}$ deficiency) among sailors, and its treatment with oranges, was registered as far back as 1498 [2]. Vitamins $\mathrm{A}$ and $\mathrm{C}$ also have a lengthy and rich history in scientific literature; in 1753 James Lind described the first controlled clinical trial where various antiscorbutic treatments were tested on British seamen and in 1929, Frederick Gowland Hopkins was co-awarded the Nobel Prize in Medicine for the 'discovery of vitamins' following milk supplementation experiments in vitamin A deficient mice [3]. Eventual isolation of the respective compounds underlying both vita- mins led to Nobel Prizes in Chemistry and Medicine in 1937 [4]. Since this time, a considerable amount of scientific progress (and at times conjecture) has been associated with vitamins $\mathrm{A}$ and $\mathrm{C}$, and their respective biological effects touch disciplines as divergent as development and dermatology.

One of the most recently discovered fields that vitamins $A$ and $C$ impact upon is epigenetics [5-7]. New research has shown that both vitamins drive active removal of DNA methylation in embryonic stem cells (ESCs) by enhancing the same family of ten-eleven translocation (TET) enzymes, and in doing so, help erase DNA methylation and the epigenetic memory encoded by it to improve the reprogramming of differentiated cells to an embryonic-like state. Here I review the effects of vitamins A and C on DNA methylation and epigenetic memory in stem cells, and outline their significance for the fields
Timothy A Hore

Department of Anatomy, University of Otago, 270 Great King Street, Dunedin, 9016, New Zealand tim.hore@otago.ac.nz 
(A)

\section{Vitamin A}<smiles>CC1=C(/C=C/C(C)=C/C=C/C(C)=C/CO)C(C)(C)CCC1</smiles><smiles>CC1=C(/C=C/C(C)=C/C=C/C(C)=C/C(=O)O)C(C)(C)CCC1</smiles>

Retinoic acid
Vitamin C<smiles>O=C1OC(C(O)CO)C([O-])=C1O</smiles>

Ascorbate
(B)

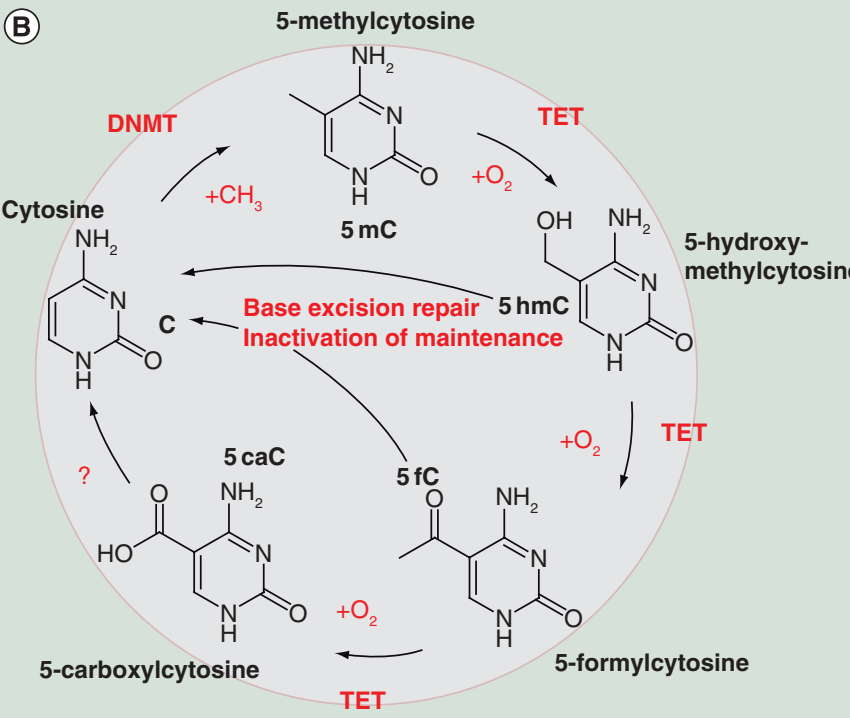

(C)

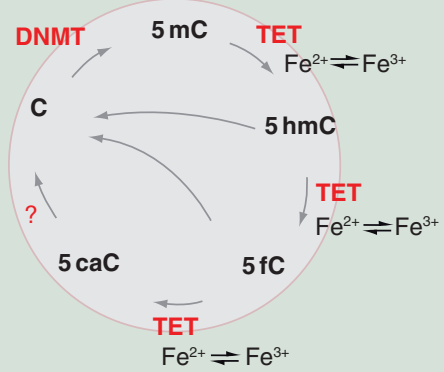

(D)

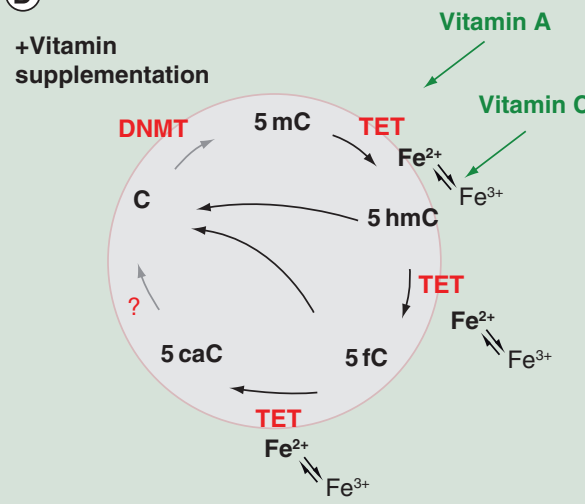

Figure 1. Vitamin A, Vitamin C and DNA demethylation. (A) The most common form of vitamin A in the body is retinol (top left), a lipid soluble molecule which can be metabolized into retinoic acid (bottom left), a signaling factor and powerful developmental morphogen. The hydrophilic ascorbate ion (right) is the most common form of vitamin $\mathrm{C}$ at physiological pH, and is well known for its antioxidant effects in cells. (B) The 'life-cycle' of cytosine variants is depicted, whereby cytosine can first be methylated by members of the DNA methyltransferase (DNMT) family of enzymes to produce 5 -methylcytosine $(5 \mathrm{mC})$. Although this is the predominant form of modified cytosine, oxidation of $5 \mathrm{mC}$ can occur to create 5 -hydroxymethylcytosine $(5 \mathrm{hmC}$ ) and further oxidized derivatives 5 -formylcytosine $(5 \mathrm{fC})$ and 5 -carboxylcytosine $(5 \mathrm{caC})$. This iterative oxidation is due to the TET family of $\mathrm{Fe}^{2+}$ - and oxoglutarate-dependent enzymes. Once oxidized to $5 \mathrm{hmC}, 5 \mathrm{fC}$ or $5 \mathrm{caC}$, cytosine derivatives can be returned to the original unmodified state through either base-excision repair pathways or as yet uncharacterized decarboxylation (indicated with a question mark). Alternatively, because DNA methylation maintenance machinery cannot recognize $5 \mathrm{hmC}-5 \mathrm{caC}$, methylation marks can effectively be removed by an 'active-passive' mechanism following replication. When naive pluripotent stem cells are subjected to conventional cell culture (C), an equilibrium for cytosine variants is determined by the rates of conversion between them. When culture media is supplemented with vitamins $A$ and C (D), oxidation and production of $5 \mathrm{hmC}$ is promoted relative to $5 \mathrm{mC}$. This is caused by increased TET protein levels driven by vitamin A, and enhanced $\mathrm{Fe}^{2+}$ recycling driven by vitamin $\mathrm{C}$; ultimately resulting in exaggerated DNA demethylation. TET: Ten-eleven translocation. 
of regenerative medicine, mammalian transgenics and cancer.

\section{Epigenetic memory and its removal in developmentally potent cells}

DNA methylation is an essential component of vertebrate development $[8-10]$, and exists predominantly at cytosines within CG dinucleotides. The reason why CG is favored over other nucleotide contexts relates to its palindromic nature. During replication, methylation maintenance machinery can recognize CG on a template strand and copy its methylation signal to the complementary CG on the newly synthesized strand [11,12]. In this way, CG can harbor molecular memory long term using a stable, but malleable, encoding system. In contrast, except following genetic manipulation [13,14], other epigenetic modifications (such as histone methylation or acetylation) do not have an equivalent capacity to maintain specific marks in long term [15].

High levels of CG methylation (70-85\%) are found throughout the somatic tissues of humans and mice $[16,17]$. However, earlier in development, naive 'pluripotent' cells within the blastocyst (which go on to form all cells and tissues of the body) display only 20-30\% CG methylation [18]. Equally low levels of methylation are also seen in cultured cells recently found to recapitulate the naive pluripotent characteristics of the early embryo [19-24]. Rapid increases in DNA methylation occur when naive cells exit pluripotency and commit to various developmental trajectories around the time of implantation (reviewed [25]). By imparting unique methylation patterns at enhancers and gene promoters (thus reflecting equally unique gene expression profiles), de novo methyltransferases have the ability to drive and consolidate early developmental decisions. In this way, CG methylation and the epigenetic memory it encodes provides a mechanism for cells to faithfully maintain a uniquely differentiated identity in the absence of the cues that defined them.

Reversal of the differentiation process and creation of cells with high developmental potency appears to be intimately linked with the removal of DNA methylation. Inhibition of DNA methylation maintenance machinery, using RNA interference or small molecules such as 5-azacytidine, has been known for some time to dramatically improve the efficiency at which induced pluripotent stem cells (iPSCs) can be reprogrammed from differentiated cells $[26,27]$. Indeed, the UHRF1 protein, which is essential for maintenance of methylation following replication, is significantly downregulated (and at times loses nuclear localization) during iPSC reprogramming, primordial germ cell definition and in the naive pluripotent state [28-30], a process likely responsible for the majority of demethylation in these systems [31].

Nevertheless, active removal of DNA methylation makes a significant contribution to epigenetic reprogramming events. The TET proteins are $\mathrm{Fe}^{2+}$ - and oxoglutarate-dependent enzymes that demethylate DNA by oxidizing methylated cytosine (i.e., 5-methylcytosine, or $5 \mathrm{mC}$ short) to 5-hydroxymethylcytosine $(5 \mathrm{hmC})$ and further oxidized derivatives [32,33]. In similar fashion to suppressors of DNA methylation maintenance machinery, forced expression of the TET proteins profoundly improves iPSC derivation [34-37]. At least part of TET function in this capacity appears to be related to removal of DNA methylation from pluripotency related genes, and as a consequence, greater activation of the pluripotency network [38-40]. While there is some redundancy between members of the TET family, the presence of at least one TET para$\log$ is essential for the production of iPSCs and normal mouse development [41-44].

Both vitamin A and vitamin C enhance DNA demethylation in naive ESCs by acting on the TET family of proteins $[37,45]$. This convergence in function is somewhat surprising given the vastly different physical and biological characteristics of these molecules. The most common form of vitamin A in the body is retinol. This lipid-soluble molecule metabolizes into retinoic acid (Figure 1A), a powerful developmental morphogen responsible for activating many genes in the 'retinoic acid signaling pathway' [46]. In contrast, the most common form of vitamin $\mathrm{C}$ is ascorbate, a water-soluble compound that functions predominantly as a reducing agent. Nevertheless, by complementary mechanisms they synergistically enhance DNA demethylation through the TET proteins, and in turn, help drive reprogramming to pluripotency.

\section{Vitamin A enhances TET expression, vitamin C potentiates TET activity}

Despite their requirement in the human diet, vitamins $\mathrm{A}$ and $\mathrm{C}$ are only sporadically included in defined cell culture formulations [47]. A comparison of media types commonly used to culture naive ESCs revealed that vitamin $\mathrm{A}$ in the form of retinyl acetate, retinol or retinoic acid can support up to $27 \%$ more $5 \mathrm{hmC}$ in the genome, and reduces $5 \mathrm{mC}$ by a similar proportion [37]. By utilizing multiple knockout ESC lines, it was shown that this demethylation was specific to transcriptional activation of TET2, and to a lesser extent TET3. Analysis of chromatin immunoprecipitation and sequencing (ChIP-seq) data [48] revealed that although Tet1 and Tet3 do not appear to be targeted directly by retinoic acid signaling, the first intron of 
the Tet 2 gene possesses a retinoic acid receptor-binding site that is conserved throughout eutherian evolution. Deletion of this site rendered TET2 mRNA insensitive to activation by retinoids [37].

Ascorbate has been shown on numerous occasions to increase $5 \mathrm{hmC}$ and decrease $5 \mathrm{mC}$ in ESCs, however, in contrast to vitamin A, this occurs without any change in TET expression [37,45,49-51]. Ascorbate is a well-characterized reducing agent which acts on $\mathrm{Fe}^{3+}$ ions, and given that $\mathrm{Fe}^{2+}$ is essential for TET activity, it was implicitly assumed that the antioxidative capacity of ascorbate is what accounts for increased $5 \mathrm{hmC}$ deposition in its presence [52]. Under this scenario, ascorbate would be better thought of as a salvager of TET catalysis following 'uncoupled' oxidation in the absence of substrate (which results in the production of $\mathrm{Fe}^{3+}$ ), rather than a cofactor intrinsically required for its activity. Nevertheless, initial biochemical studies did not support this contention; reducing agents other than ascorbate were apparently insufficient to enhance TET activity in vitro $[45,50,51,53]$. Subsequent cell culture experiments using quinones as reducing agents [54,55], and further in vitro experiments at physiological $\mathrm{pH}$ [37] have now challenged this conclusion. Ascorbate has been found not to enhance TET activity when in the presence of sufficient $\mathrm{Fe}^{2+}$, demonstrating it is not an obligatory cofactor [37]. Moreover, with sufficient reaction time, TET activity can be rescued in vitro by antioxidants other than ascorbate (including hydroquinone) through reduction of $\mathrm{Fe}^{3+}$ to $\mathrm{Fe}^{2+}$.

Interestingly, vitamin $\mathrm{C}$ appears to also exert an effect upon other epigenetic modifications. Histone demethylases, such as those within the Jumonji C $(\mathrm{JmjC})$ family, function in an analogous manner to the TET proteins - hydroxylation by JmjC proteins similarly initiates histone methylation removal, and like the TET family, JmjC enzymes are $\mathrm{Fe}^{2+}$ and oxoglutarate dependent [56]. Vitamin $\mathrm{C}$ is essential for the activity of the JmjC demethylase in vitro, and was recently shown to drive expression of IL17 following vitamin C supplementation, not TET [57]. As such, it is likely important to use model systems where the TET or JmjC proteins can be specifically attenuated in order to grasp the true effect of vitamin $\mathrm{C}$ supplementation for a given gene. Indeed, this may also be true for vitamin A which has been reported to affect histone methylation by as yet unexplored mechanisms [58].

\section{Vitamins A \& C in regenerative medicine \& mammalian transgenics: is tuning required?} Naive pluripotent stem cells, particularly those which are patient derived (such as iPSCs), hold great promise for the field of regenerative medicine because they can be grown in culture and have unrivaled developmental capacity [59]. Equally, naive stem cells from nonrodent models could revolutionize mammalian transgenics in a similar fashion to classically grown ESCs and the knockout mouse, allowing complex genetic modification techniques to be applied to a wide range of mammalian systems, including those more effectively modeling human physiology. Both vitamins $\mathrm{A}$ and $\mathrm{C}$ are known to improve the efficiency at which iPSCs can be generated from differentiated cells $[37,60,61]$, and when cosupplemented, display additive and enhanced synergistic effects upon demethylation and reprogramming, respectively [37]. As such, it is likely that pluripotent cell media formulations developed in the future for regenerative medicine and mammalian transgenics will include optimized amounts of both vitamins.

Nevertheless, naive stem cell culture conditions are associated with risks that are not yet fully understood. Reprogramming of conventional mouse and human ESCs (which are 'primed' for differentiation) to naive pluripotency involves global reduction of CG methylation from $70-75 \%$ to $20-30 \%$ [19-21], and with vitamin supplementation this can get even lower [62]. Imprinting control regions (ICRs) which orchestrate parent specific gene expression of approximately 100 mammalian genes (including growth factors) are generally resistant to demethylation in naive ESCs [19,63]. Nevertheless, activation of normally silenced imprinted alleles can occur under naive conditions due to excessive demethylation, and once lost from an ICR, parent-specific methylation cannot be recovered [62]. Given that loss of imprinting is a known driver of developmental disease and cancer [64,65], its occurrence in naive cells would render them unsafe for clinical and transgenics applications. ICR erasure in primordial germ cells is thought to involve TET protein action [66-69], and as such, it is not unreasonable to expect that loss of imprinting in naive ESCs could be exacerbated by supplementation of vitamins $\mathrm{A}$ and $\mathrm{C}$. This means that in order to strike a balance between imprinting fidelity in naive pluripotent stem cells and the efficiency at which they are derived, fine-tuning of vitamin levels and TET activity may be required (Figure 2).

\section{Vitamins, TET \& cancer treatment}

Many tumors and cultured cancer cell lines are subjected to global hypomethylation that is superficially similar to demethylation in pluripotent stem cells and the germline $[17,70,71]$. Currently it is unclear how global hypomethylation of a cell may contribute to tumorigenesis, with genomic instability, oncogene activation and increased recombination all predicted to be 
(A) \begin{tabular}{cc}
\multicolumn{2}{c}{ Low TET activity } \\
$\begin{array}{c}\text { Pluripotency } \\
\text { genes }\end{array}$ \\
Imprinted \\
genes
\end{tabular}

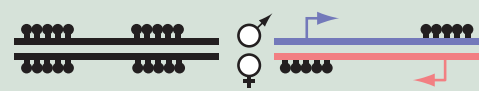
4

\section{High TET activity}

$$
\begin{array}{cc}
\begin{array}{c}
\text { Pluripotency } \\
\text { genes }
\end{array} & \text { Imprinted } \\
& \text { genes }
\end{array}
$$

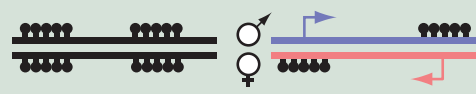

Reprogramming
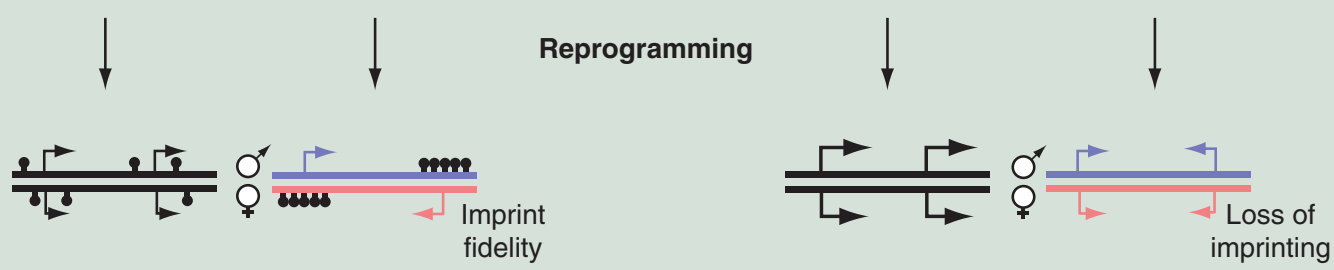

(B) Relative TET activity

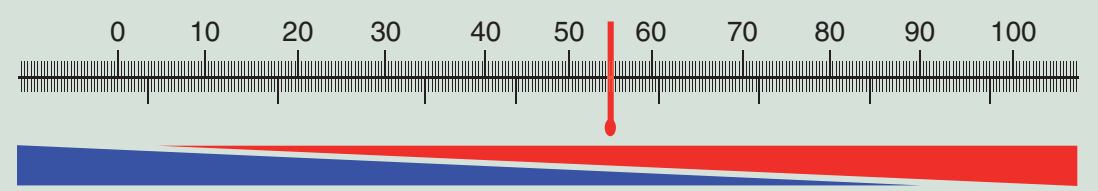

Safety
Efficiency

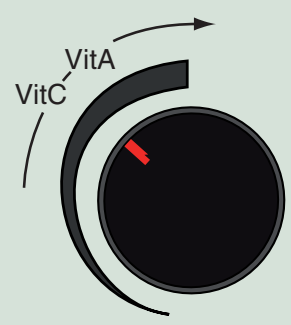

Figure 2. Tuning TET function for the efficient and safe production of naive pluripotent stem cells. (A) Increased TET levels and activity enhance reprogramming of differentiated cells to the naive pluripotent state by removing DNA methylation (black lollipops) from promoters and other cis-elements allowing increased expression of pluripotency genes (large black arrows). Nevertheless, this same process may also increase the likelihood of loss of methylation from both maternal (red) and paternal (blue) alleles at imprinted genes, an outcome which would preclude affected pluripotent cells from being used in regenerative medicine and mammalian transgenics. Accordingly, 'tuning' TET levels and activity (B) by modulating vitamins A and C supplementation (black control dial) may be an important step in exploiting the full potential of naive pluripotent cells.

involved [71]. Irrespective of the mechanism, like pluripotent stem cells, cancers have an increased capacity for proliferation and transforming into divergent cell types; an ability, which may be further enabled by global hypomethylation of the genome.

Despite these parallels, there is one striking difference between the epigenome of pluripotent cells and cancer cells. Many gene promoters become hypermethylated in cancer, causing silencing of tumor suppressor genes [72]. TET proteins are thought to drive a significant number of these hypermethylation events through at least two mechanisms. First, genetic mutation of TET is a common feature of many cancers, especially hematological malignancies [73]. Indeed, TET derives its name from translocations between chromosomes 10 and 11, which are associated with acute myeloid leukemia subtypes [74]. Alternatively, in solid tumors, TET can be indirectly affected by hypoxic conditions $\left(<0.5 \% \mathrm{O}_{2}\right)$, essentially choking catalytic activity by removal of the obligate oxygen substrate [75,76]. Considering this, and the observation that low $5 \mathrm{hmC}$ production is a marker of many cancers and particularly poor clinical outcome, TET proteins are considered to be genuine tumor suppressor genes [73].

Could activation of TET and restoration of normal $5 \mathrm{hmC}$ levels and DNA methylation patterns using vitamin supplementation provide some value in the treatment of cancer? The benefit of high doses of ascorbate in broad-spectrum cancer treatment was initially reported by Cameron and Pauling [77]; however, subsequent trials have either shown promising benefits in certain circumstances, or have provided no detectable advantages at all [78-84]. Nevertheless, it remains possible that vitamin $\mathrm{C}$ supplementation can reverse global loss of $5 \mathrm{hmC}[6]$ and hypermethylation of tumor-suppressor genes [75,76]. In support of this proposition, it has been found that a high proportion of cancer patients are actually deficient in vitamin $\mathrm{C}$ [84]. Interestingly, in vitro modeling experiments have shown that vitamin C amplifies the anticancer effects of decitabine, a drug commonly used in treatment of hematological malignancies and well-described driver of DNA demethylation [85]. It will be important to explore this initial work with mechanistic understanding of how 
vitamin $C$ (and decitabine) interact with cancer cells, and ultimately, advanced testing in a clinical setting where ascorbate delivery and pharmacokinetics can be effectively controlled.

In contrast to vitamin $\mathrm{C}$, it is well accepted that vitamin $\mathrm{A}$ in the form of retinoic acid is an effective component of certain cancer treatments, in particular, those for acute promyelocytic leukemia (APL) [86]. APL is characterized by production of a fusion oncoprotein between PML and retinoic acid receptor $\alpha$, the cause of which is a chromosomal translocation detectable in $>98 \%$ of patients [87]. The PML-retinoic acid receptor $\alpha$ oncoprotein represses many of the canonical genes targeted by retinoic acid signaling, and in doing so, blocks myeloid differentiation. Pharmacological doses of retinoic acid can reverse this silencing and when used in combination with arsenic trioxide, differentiation treatment of APL using retinoic acid can provide 5-year event-free survival rates of $>90 \%$ [88], a stunning outcome for what was in the 1970s, a most deadly form of acute leukemia.

Despite these successes, some patients are resistant to differentiation therapy using retinoic acid. Given that mutations in TET2 are well-known for their ability to suppress differentiation of myeloid lineages and drive malignancy $[73,89]$, and TET2 is a direct target of the retinoic acid signaling pathway [37], it seems possible that instances of retinoic acid insensitivity in APL patients are due to TET2 mutation. Supporting this hypothesis is the finding that $4.5 \%$ of APL patients possess TET2 mutation, and along with disruption of several other epigenetic modifiers predicts poor treatment outcome [90]. If proven by further experimentation, diagnostic testing of TET2 mutation profiles in APL patients could assist treatment management.

\section{Future perspective}

Vitamins A and C are well-known dietary components that have recently been shown to impact upon the erasure of epigenetic memory in pluripotent cell types by modulating TET protein abundance and potentiating its activity. While it is unclear what impact these vitamins have on the epigenetic status of differentiated cells, optimizing their effects in order to efficiently produce and maintain naive pluripotent cell types which are safe for regenerative medicine and mammalian transgenics will be a future challenge. Furthermore, elucidation of the effects that vitamins A and C have on malignant cell types could have far-reaching implications for understanding the biology of cancer and enhancing its treatment.

\section{Acknowledgements}

I would like to sincerely acknowledge the contribution of colleagues and co-authors in helping to develop the data and ideas underlying this review. I am also grateful to D Bond for critical reading of the manuscript.

\section{Financial \& competing interests disclosure}

Funding for the author is provided by a University of Otago Research Grant and Departmental support. The author has no other relevant affiliations or financial involvement with any organization or entity with a financial interest in or financial conflict with the subject matter or materials discussed in the manuscript apart from those disclosed.

No writing assistance was utilized in the production of this manuscript.

\section{Open access}

This work is licensed under the Attribution-NonCommercialNoDerivatives 4.0 Unported License. To view a copy of this license, visit http://creativecommons.org/licenses/by-nc-nd/4.0/

\section{Executive summary}

- Vitamins A and C reduce epigenetic memory in naive embryonic stem cells (ESCs) in a manner that is dependent upon the demethylating ten-eleven translocation (TET) proteins.

- Vitamin A (retinol, retinoic acid) enhances TET2 expression in naive ESCs via the retinoic acid signaling pathway.

- Vitamin C (ascorbate) enhances TET activity by potentiating TET catalytic activity.

- Vitamins A and C act synergistically to enhance production of induced pluripotent stem cells from differentiated cell types.

- Optimizing appropriate TET levels and activity will be important for the efficient and safe production/ maintenance of naive pluripotent cells used for regeneration medicine and mammalian transgenics.

- A greater understanding of how vitamins A and C impact upon TET and the epigenome may have clinical relevance in cancer, particularly acute promyelocytic leukemia and other hematological malignancies.

\section{References}

Papers of special note have been highlighted as: $\bullet$ of interest;

• of considerable interest

1 Sommer A, West KP. Vitamin A Deficiency: Health,
Survival and Vision. Oxford University Press, Inc., NY, USA (2001).

2 Carpenter KJ. The History of Scurvy and Vitamin C.

Cambridge University Press, Cambridge, UK (1988). 
3 Semba RD. On the "discovery" of vitamin A. Ann. Nutr. Metab. 61(3), 192-198 (2012).

4 Souganidis E. Nobel laureates in the history of the vitamins. Ann. Nutr. Metab. 61(3), 265-269 (2012).

5 Young JI, Züchner S, Wang G. Regulation of the epigenome by vitamin C. Annu. Rev. Nutr. 35, 545-564 (2015).

6 Camarena V, Wang G. The epigenetic role of vitamin C in health and disease. Cell. Mol. Life Sci. 73(8), 1645-1658 (2016).

7 Dadon Bar-El S, Reifen R. Vitamin A and the epigenome. Crit. Rev. Food Sci. Nutr. (2015) (Epub ahead of print).

8 Okano M, Bell DW, Haber DA, Li E. DNA methyltransferases Dnmt3a and Dnmt3b are essential for de novo methylation and mammalian development. Cell 99(3), 247-257 (1999).

9 Li E, Bestor TH, Jaenisch R. Targeted mutation of the DNA methyltransferase gene results in embryonic lethality. Cell 69(6), 915-926 (1992).

10 Rai K, Nadauld LD, Chidester S et al. Zebra fish Dnmt1 and Suv39h1 regulate organ-specific terminal differentiation during development. Mol. Cell. Biol. 26(19), 7077-7085 (2006).

11 Goll MG, Bestor TH. Eukaryotic cytosine methyltransferases. Annu. Rev. Biochem. 74(1), 481-514 (2005).

12 Li E, Zhang Y. DNA methylation in mammals. Cold Spring Harb. Perspect. Biol. 6(5), a019133 (2014).

- Comprehensive and recent review of DNA methylation in mammals, and its mechanisms of removal.

13 Audergon PNCB, Catania S, Kagansky A et al. Epigenetics. Restricted epigenetic inheritance of $\mathrm{H} 3 \mathrm{~K} 9$ methylation. Science (New York, NY). 348(6230), 132-135 (2015).

14 Ragunathan K, Jih G, Moazed D. Epigenetics. Epigenetic inheritance uncoupled from sequence-specific recruitment. Science 348(6230), 1258699 (2014).

15 Bintu L, Yong J, Antebi YE et al. Dynamics of epigenetic regulation at the single-cell level. Science 351(6274), 720-724 (2016).

16 Hon GC, Rajagopal N, Shen Y et al. Epigenetic memory at embryonic enhancers identified in DNA methylation maps from adult mouse tissues. Nat. Genet. 45(10), 1198-1206 (2013).

17 Ziller MJ, Gu H, Müller F et al. Charting a dynamic DNA methylation landscape of the human genome. Nature 500 (7463), 477-481 (2013).

18 Smith ZD, Chan MM, Humm KC et al. DNA methylation dynamics of the human preimplantation embryo. Nature 511(7511), 611-615 (2014).

19 Ficz G, Hore TA, Santos F et al. FGF signaling inhibition in ESCs drives rapid genome-wide demethylation to the epigenetic ground state of pluripotency. Cell Stem Cell 13(3), 351-359 (2013).

20 Habibi E, Brinkman AB, Arand J et al. Whole-genome bisulfite sequencing of two distinct interconvertible DNA methylomes of mouse embryonic stem cells. Cell Stem Cell 13(3), 360-369 (2013).
21 Takashima Y, Guo G, Loos R et al. Resetting transcription factor control circuitry toward ground-state pluripotency in human. Cell 158(6), 1254-1269 (2014).

22 Theunissen TW, Friedli M, He Y et al. Molecular criteria for defining the naive human pluripotent state. Cell Stem Cell 19(4), 502-515 (2016).

23 Gafni O, Weinberger L, Mansour AA et al. Derivation of novel human ground state naive pluripotent stem cells. Nature 504(7479), 282-286 (2013).

24 Leitch HG, McEwen KR, Turp A et al. Naive pluripotency is associated with global DNA hypomethylation. Nat. Struct. Mol. Biol. 20 (3), 311-316 (2013).

25 Lee HJ, Hore TA, Reik W. Reprogramming the methylome: erasing memory and creating diversity. Cell Stem Cell 14(6), 710-719 (2014).

26 Mikkelsen TS, Hanna J, Zhang X et al. Dissecting direct reprogramming through integrative genomic analysis. Nature 454(7200), 49-55 (2008).

- In addition to being one of the first accurate molecular descriptions of stem cell reprogramming, this paper establishes that suppression of DNA methylation can enhance reprogramming efficiency.

27 Theunissen TW, van Oosten AL, Castelo-Branco G, Hall J, Smith A, Silva JCR. Nanog overcomes reprogramming barriers and induces pluripotency in minimal conditions. Curr. Biol. 21(1), 65-71 (2011).

28 von Meyenn F, Iurlaro M, Habibi E et al. Impairment of DNA methylation maintenance is the main cause of global demethylation in naive embryonic stem cells. Mol. Cell 62(6), 848-861 (2016).

29 Milagre I, Stubbs TM, King MR et al. Gender differences in global but not targeted demethylation in iPSC reprogramming. Cell Rep. 18(5), 1079-1089 (2017).

30 Seisenberger S, Andrews S, Krueger F et al. The dynamics of genome-wide DNA methylation reprogramming in mouse primordial germ cells. Mol. Cell 48(6), 849-862 (2012).

31 Iurlaro M, von Meyenn F, Reik W. DNA methylation homeostasis in human and mouse development. Curr. Opin. Genet. Dev. 43(1), 101-109 (2017).

32 Tahiliani M, Koh KP, Shen Y et al. Conversion of 5-methylcytosine to 5-hydroxymethylcytosine in mammalian DNA by MLL partner TET1. Science 324(5929), 930-935 (2009).

- This landmark paper identified that ten-eleven translocation (TET) proteins are responsible for the oxidation of 5-methylcytosine to 5-hydroxymethylcytosine. In doing so, this work uncovered a major pathway that actively erases epigenetic memory.

33 Ito $S$, Shen L, Dai Q et al. Tet proteins can convert 5-methylcytosine to 5-formylcytosine and 5-carboxylcytosine. Science 333(6047), 1300-1303 (2011).

34 Gao Y, Chen J, Li K et al. Replacement of Oct 4 by Tet1 during iPSC induction reveals an important role of DNA methylation and hydroxymethylation in reprogramming. Cell Stem Cell 12(4), 453-469 (2013). 
35 Doege C, Inoue K, Yamashita T et al. Early-stage epigenetic modification during somatic cell reprogramming by Parp1 and Tet2. Nature 488(7413), 652-655 (2012).

36 Costa Y, Ding J, Theunissen TW et al. NANOGdependent function of TET1 and TET2 in establishment of pluripotency. Nature 495(7441), 370-374 (2013).

37 Hore TA, von Meyenn F, Ravichandran M et al. Retinol and ascorbate drive erasure of epigenetic memory and enhance reprogramming to naive pluripotency by complementary mechanisms. Proc. Natl Acad. Sci. USA 113(43), 12202-12207 (2016).

-. This publication demonstrated that vitamins A and C synergistically help erasure of epigenetic memory in naive pluripotent cells.

38 Williams K, Christensen J, Pedersen MT et al. TET1 and hydroxymethylcytosine in transcription and DNA methylation fidelity. Nature 473(7347), 343-348 (2011).

39 Ficz G, Branco MR, Seisenberger $S$ et al. Dynamic regulation of 5-hydroxymethylcytosine in mouse ES cells and during differentiation. Nature 473(7347), 398-402 (2011).

40 Wu H, D’Alessio AC, Ito $S$ et al. Genome-wide analysis of 5-hydroxymethylcytosine distribution reveals its dual function in transcriptional regulation in mouse embryonic stem cells. Genes Dev. 25(7), 679-684 (2011).

41 Dawlaty MM, Breiling A, Le T et al. Loss of tet enzymes compromises proper differentiation of embryonic stem cells. Dev. Cell 29(1), 102-111 (2014).

42 Dawlaty MM, Ganz K, Powell BE et al. Tet1 is dispensable for maintaining pluripotency and its loss is compatible with embryonic and postnatal development. Cell Stem Cell 9(2), 166-175 (2011).

43 Dawlaty MM, Breiling A, Le T et al. Combined deficiency of Tet 1 and Tet 2 causes epigenetic abnormalities but is compatible with postnatal development. Dev. Cell 24(3), 310-323 (2013).

44 Hu X, Zhang L, Mao SQ et al. Tet and TDG mediate DNA demethylation essential for mesenchymal-to-epithelial transition in somatic cell reprogramming. Cell Stem Cell 14(4), 512-522 (2014)

45 Blaschke K, Ebata KT, Karimi MM et al. Vitamin C induces Tet-dependent DNA demethylation and a blastocyst-like state in ES cells. Nature 500(7461), 222-226 (2013).

- The first demonstration that demethylation of embryonic stem cells following vitamin $\mathrm{C}$ treatment is dependent upon the TET proteins.

46 Rhinn M, Dollé P. Retinoic acid signalling during development. Development 139(5), 843-858 (2012).

47 van der Valk J, Brunner D, De Smet Ket al. Optimization of chemically defined cell culture media - replacing fetal bovine serum in mammalian in vitro methods. Toxicol. Vitr. 24(4), 1053-1063 (2010).

48 Mahony S, Mazzoni EO, McCuine S, Young RA, Wichterle $\mathrm{H}$, Gifford DK. Ligand-dependent dynamics of retinoic acid receptor binding during early neurogenesis. Genome Biol. 12(1), R2 (2011).
49 Chung T-L, Brena RM, Kolle G et al. Vitamin C promotes widespread yet specific DNA demethylation of the epigenome in human embryonic stem cells. Stem Cells 28(10), 1848-1855 (2010)

50 Minor EA, Court BL, Young JI, Wang G. Ascorbate induces ten-eleven translocation (Tet) methylcytosine dioxygenasemediated generation of 5-hydroxymethylcytosine. J. Biol. Chem. 288(19), 13669-13674 (2013).

51 Yin R, Mao S-Q, Zhao B et al. Ascorbic acid enhances Tetmediated 5-methylcytosine oxidation and promotes DNA demethylation in mammals. J. Am. Chem. Soc. 135(28), 10396-10403 (2013).

52 Monfort A, Wutz A. Breathing-in epigenetic change with vitamin C. EMBO Rep. 14(4), 337-346 (2013).

53 Dickson KM, Gustafson CB, Young JI, Züchner S, Wang G. Ascorbate-induced generation of 5-hydroxymethylcytosine is unaffected by varying levels of iron and 2-oxoglutarate. Biochem. Biophys. Res. Commun. 439(4), 522-527 (2013).

54 Coulter JB, O’Driscoll CM, Bressler JP. Hydroquinone increases 5-hydroxymethylcytosine formation through ten eleven translocation 1 (TET1) 5-methylcytosine dioxygenase. J. Biol. Chem. 288(40), 28792-28800 (2013).

55 Zhao B, Yang YY-G, Wang X et al. Redox-active quinones induces genome-wide DNA methylation changes by an ironmediated and Tet-dependent mechanism. Nucleic Acids Res. 42(3), 1593-1605 (2014).

56 Tsukada Y, Fang J, Erdjument-Bromage $\mathrm{H}$ et al. Histone demethylation by a family of JmjC domain-containing proteins. Nature 439(7078), 811-816 (2006).

57 Song MH, Nair VS, Oh KI. Vitamin C enhances the expression of IL17 in a Jmjd2-dependent manner. BMB Rep. 50(1), 49-54 (2017).

58 Arts RJW, Blok BA, van Crevel R et al. Vitamin A induces inhibitory histone methylation modifications and downregulates trained immunity in human monocytes. J. Leukoc. Biol. 98(1), 129-136 (2015).

59 Tabar V, Studer L. Pluripotent stem cells in regenerative medicine: challenges and recent progress. Nat. Rev. Genet. 15(2), 82-92 (2014)

60 Chen J, Liu J, Chen Y et al. Rational optimization of reprogramming culture conditions for the generation of induced pluripotent stem cells with ultra-high efficiency and fast kinetics. Cell Res. 21(6), 884-894 (2011).

61 Yang J, Wang W, Ooi J, Campos LS, Lu L, Liu P. Signalling through retinoic acid receptors is required for reprogramming of both mouse embryonic fibroblast cells and epiblast stem cells to induced pluripotent stem cells. Stem Cells 33(5), 1390-1404 (2015).

- The first demonstration that vitamin A and retionic acid signaling is an essential component of stem cell reprogramming.

62 Greenberg MV, Bourc'his D. Cultural relativism: maintenance of genomic imprints in pluripotent stem cell culture systems. Curr. Opin. Genet. Dev. 31, 42-49 (2015).

63 Hackett JA, Dietmann S, Murakami K, Down TA, Leitch HG, Surani MA. Synergistic mechanisms of 
DNA demethylation during transition to ground-state pluripotency. Stem Cell Rep. 1(6), 518-531 (2013).

64 Peters $J$. The role of genomic imprinting in biology and disease: an expanding view. Nat. Rev. Genet. 15(8), 517-530 (2014).

65 Jelinic P, Shaw P. Loss of imprinting and cancer. J. Pathol. 211(3), 261-268 (2007).

66 Seisenberger S, Andrews S, Krueger F et al. The dynamics of genome-wide DNA methylation reprogramming in mouse primordial germ cells. Mol. Cell. 48(6), 849-862 (2012).

67 Hackett JA, Sengupta R, Zylicz JJ et al. Germline DNA demethylation dynamics and imprint erasure through 5-hydroxymethylcytosine. Science 339 (6118), 448-452 (2013).

68 Vincent JJ, Huang Y, Chen P-Y et al. Stage-specific roles for Tet1 and Tet2 in DNA demethylation in primordial germ cells. Cell Stem Cell 12(4), 470-478 (2013).

69 Yamaguchi S, Shen L, Liu Y, Sendler D, Zhang Y. Role of Tet1 in erasure of genomic imprinting. Nature 504(7480), 460-464 (2013)

70 Gama-Sosa MA, Slagel VA, Trewyn RW et al. The 5-methylcytosine content of DNA from human tumors. Nucleic Acids Res. 11(19), 6883-6894 (1983).

71 Ehrlich M. DNA hypomethylation in cancer cells. Epigenomics 1(2), 239-259 (2009).

72 Baylin SB, Herman JG. Gene silencing in cancer in association with promoter hypermethylation. $N$. Engl. J. Med. 349 (21), 2042-2054 (2003).

73 Huang $\mathrm{Y}$, Rao A. Connections between TET proteins and aberrant DNA modification in cancer. Trends Genet. 30(10), 464-474 (2014).

74 Lorsbach RB, Moore J, Mathew S, Raimondi SC, Mukatira ST, Downing JR. TET1, a member of a novel protein family, is fused to MLL in acute myeloid leukemia containing the $\mathrm{t}(10 ; 11)(\mathrm{q} 22 ; \mathrm{q} 23)$. Leukemia 17(3), 637-641 (2003).

75 Thienpont B, Steinbacher J, Zhao H et al. Tumour hypoxia causes DNA hypermethylation by reducing TET activity. Nature 537(7618), 63-68 (2016).

- Demonstrates for the first time that hypoxia within cancers can drive hypermethylation of gene promoters due to the TET proteins lacking $\mathrm{O}_{2}$, a key reaction substrate.

76 Thienpont B, Galle E, Lambrechts D. TET enzymes as oxygen-dependent tumor suppressors: exciting new avenues for cancer management. Epigenomics 8(11), 1445-1448 (2016).

77 Cameron E, Pauling L. Supplemental ascorbate in the supportive treatment of cancer: reevaluation of prolongation of survival times in terminal human cancer. Proc. Natl Acad. Sci. USA 75(9), 4538-4542 (1978).
78 Moertel CG, Fleming TR, Creagan ET, Rubin J, O'Connell MJ, Ames MM. High-dose vitamin $\mathrm{C}$ versus placebo in the treatment of patients with advanced cancer who have had no prior chemotherapy. A randomized double-blind comparison. N. Engl. J. Med. 312(3), 137-141 (1985).

79 Creagan ET, Moertel CG, O'Fallon JR et al. Failure of highdose vitamin $\mathrm{C}$ (ascorbic acid) therapy to benefit patients with advanced cancer. A controlled trial. N. Engl. J. Med. 301(13), 687-690 (1979).

80 Padayatty SJ, Riordan HD, Hewitt SM, Katz A, Hoffer LJ, Levine M. Intravenously administered vitamin $\mathrm{C}$ as cancer therapy: three cases. CMAJ 174(7), 937-942 (2006).

81 Monti DA, Mitchell E, Bazzan AJ et al. Phase I evaluation of intravenous ascorbic acid in combination with gemcitabine and erlotinib in patients with metastatic pancreatic cancer. PLoS ONE 7(1), e29794 (2012).

82 Welsh JL, Wagner BA, van't Erve TJ et al. Pharmacological ascorbate with gemcitabine for the control of metastatic and node-positive pancreatic cancer (PACMAN): results from a phase I clinical trial. Cancer Chemother. Pharmacol. 71(3), 765-775 (2013).

83 Parrow NL, Leshin JA, Levine M. Parenteral ascorbate as a cancer therapeutic: a reassessment based on pharmacokinetics. Antioxid. Redox Signal. 19(17), 2141-2156 (2013).

84 Kuiper C, Vissers MCM. Ascorbate as a co-factor for Feand 2-oxoglutarate dependent dioxygenases: physiological activity in tumor growth and progression. Front. Oncol. 4, 1-11 (2014).

85 Liu M, Ohtani H, Zhou W et al. Vitamin C increases viral mimicry induced by 5-aza-2'-deoxycytidine. Proc. Natl Acad. Sci. USA 113(37), 10238-10244 (2016).

86 Huang ME, Ye YC, Chen SR et al. Use of all-trans retinoic acid in the treatment of acute promyelocytic leukemia. Blood 72(2), 567-572 (1988).

87 Ablain J, de Thé $\mathrm{H}$. Retinoic acid signaling in cancer: the parable of acute promyelocytic leukemia. Int. J. Cancer 135(10), 2262-2272 (2014).

88 Lo-Coco F, Avvisati G, Vignetti M et al. Retinoic acid and arsenic trioxide for acute promyelocytic leukemia supplementary appendix. N. Engl. J. Med. 369(2), 111-121 (2013).

89 Ko M, An J, Pastor WA, Koralov SB, Rajewsky K, Rao A. TET proteins and 5-methylcytosine oxidation in hematological cancers. Immunol. Rev. 263(1), 6-21 (2015).

90 Shen Y, Fu Y-K, Zhu Y-M et al. Mutations of epigenetic modifier genes as a poor prognostic factor in acute promyelocytic leukemia under treatment with all-trans retinoic acid and arsenic trioxide. EBioMedicine 2(6), 563-571 (2015). 